\title{
Smart Quick Coupling System for Safe Equipment Attachment Selection and Operation
}

\author{
S. Rinneberg ${ }^{a}$, J. Teizer ${ }^{b}$, S. Kessler ${ }^{a}$, W.A. Günthner ${ }^{a}$ \\ ${ }^{a}$ Institute of Material Handling, Material Flow and Logistics Technical University of Munich, Germany \\ ${ }^{b}$ RAPIDS Construction Safety and Technology Laboratory, Germany \\ E-mail: rinneberg@fml.mw.tum.de,jochen@teizer.com, kessler@fml.mw.tum.de,guenthner@fml.mw.tum.de
}

\begin{abstract}
This article introduces a new approach of an intelligent equipment attachment identification system based on passive radio frequency sensing technology that provides operators with the assurance the correct attachment is used while all hydraulic functions, which are so far set manually, are maintained. The article first provides an introduction to the technology of quick coupling devices and its advantages and current limitations. Concluding from corresponding safety statistics that fatal accidents involving quick couplers are on the rise, the developed identification and control system as well as the experimental test environment and measurement procedure are introduced. Results show that an intelligent quick coupling system for equipment attachment selection and operation can provide equipment operators with additional, safe and productive alternatives to existing malfunctioning systems or practices.
\end{abstract}

Keywords - Equipment attachment selection, Human factors, Operator visibility, Quick couplers, Radio frequency identification, Safety and health.

\section{Introduction}

The construction industry has done much to improve its overall safety performance, but causes large number of deaths and serious injuries worldwide and every year [1]. As equipment design is constantly evolving and construction processes are refined to increase efficiency, quick coupling devices have been introduced that transform the use of machines from single- to multipurpose. Such popularity of more versatile pieces of construction equipment consequently safes time whilst giving contractors other benefits, for example, improved productivity and lower capital investment. Unfortunately, over the past years there has been a steady issue with accidents involving quick coupling devices that enable operators to make rapid attachment changes on construction sites. Many resulted in fatalities or serious injury. Dropping attachments and pinning workers are serious problems to an industry that has consistently raised the safety bar. The tragic cost of human suffering and other financial loss, incl. damage to the reputation of contractors and machine brands alike, make a very strong business case for improving the safety performance. The risk of injury can be easily prevented if attachments are selected correctly for the application, competent people plan its use, activities are monitored continuously, and equipment is maintained effectively and inspected adequately.

\section{Background}

The background review explains first why quickcoupling systems have become popular in construction. It explains how buckets and other attachments can be unintentionally released from quick couplers. A review of the related safety statistics alerts of the need for advanced safety systems or other preventive action.

\subsection{Quick Coupling Devices}

A quick coupler is a mechanical or hydraulic coupling used on equipment to connect different types of attachments, for example buckets, tiltrotators, compactors, hydraulic breakers and so on. They allow operators to easily change different types of attachments.

Universal and dedicated quick couplers exist. Universal pin systems attach to the standard pivot pins on the bucket, which allows a wide range of buckets to be attached, but alters the original radius of the bucket movement. Dedicated couplers are designed to specific machine or series of attachments, ensuring the original attachment geometry is maintained, but requiring eventually attachment modification so it fits the coupler [2-3].

In addition, a manual quick coupler requires the operator to leave the cab and use a tool to disengage the attachment and then engage a new attachment. Using a hydraulic quick coupler the operator can engage and 
disengage the attachment from the cabin automatically. As the latter option (a) eliminates the need for a workeron-foot to connect the attachments and (b) allows the operator to rapidly change from bigger to smaller, or other various attachments, it significantly improves the productivity of operations. Semi-automatic approaches exist as well, therefore it is an important that an operator always inspects the coupling is secure [2].

Quick couplers are mostly after-market devices. Made by various manufacturers since the late 1960s, they have been often used on hydraulic excavators and have steadily increased in popularity. Most quick couplers have a lifting eye to use for lifting material. Some designs provide users with a retrofit locking pin which is manually inserted behind the front lever (stick pion) or rear lever (link pin) to prevent unintended releases. Over time, corrective actions decreased the probability of bucket or other attachment being unintentionally released from a quick coupler connected to a piece of equipment [4].

\subsection{Related Hazards}

Not all contractors who use quick couplers are aware of the hazards they create on construction sites. They:

1. Are unaware of retrofits or corrective actions,

2. Apply no or malfunctioning locking pins, and

3. Have insufficient training on proper operation.

Although a visual indicator of an operator on a coupler shows that a connection has been made with the pins of the attachement, it does not mean that in the event of a hydraulic failure the coupler is safe for use. The attachment can still unexpectedly release, drop or swing (see Figures 1 and $2 \mathrm{a}$ ) if the safety locking mechanism are not inserted. Depending on the coupler geometry, three events can take place as a result [2]:

1. Correct coupling ( $99.99993 \%$ of all cases)

2. Miss connect, locking above the rear pin $(0.00007 \%$ or $80 \%$ of all hazardous events $)$, and

3. Miss connect, locking on the rear pin $(0.00007 \%$ or $20 \%$ of all hazard events).

Although recent technological advances have decreased likelihood of a hazard event, even if the bucket or attachment only partially falls (i.e., swings on one pin), the fall and swing is still a potential hazard which should be removed from the fundamental design of the coupler and operation of it. Such events should be recorded as near misses [5].

Mechanical back-up safety systems to automatically secure both front and rear attachment pins in the event that engagement forces are lost, prevent attachments from swinging dangerously in this event (see Figure 2a).

The fall of the attachment that pinches, hits, or crushes workers (see Figure 3) can be prevented by manual and automated checking processes. Figure $2 b$ demonstrates how operators check if a bucket is securely attached. They place a shear force when the bucket is close to the operator's cabin to test the connection.

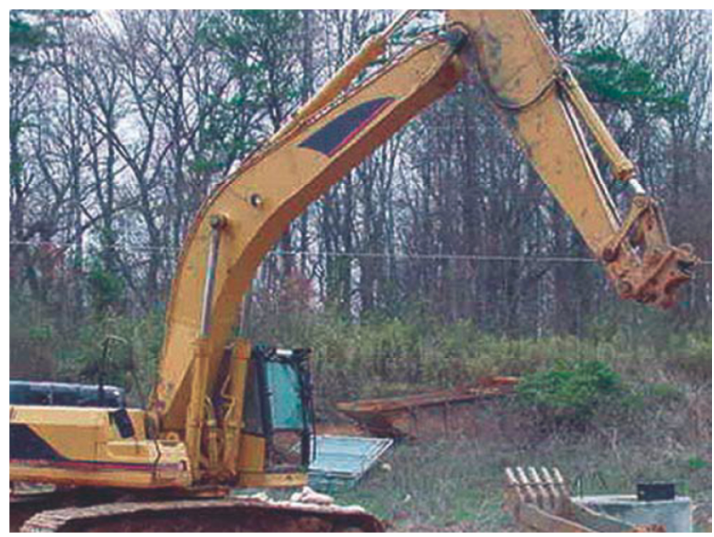

Figure 1. Malfunctioning quick coupling bucket that detached from the excavator stick [6]

(a)

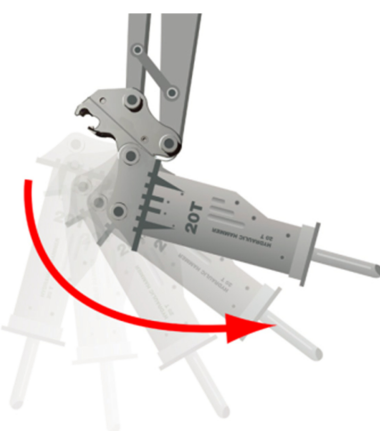

(b)

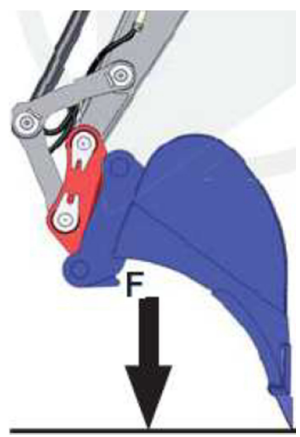

Figure 2. (a) Partial fall of attachment [7] and (b) manual approach to check the secure connection between stick and bucket (right) [8]

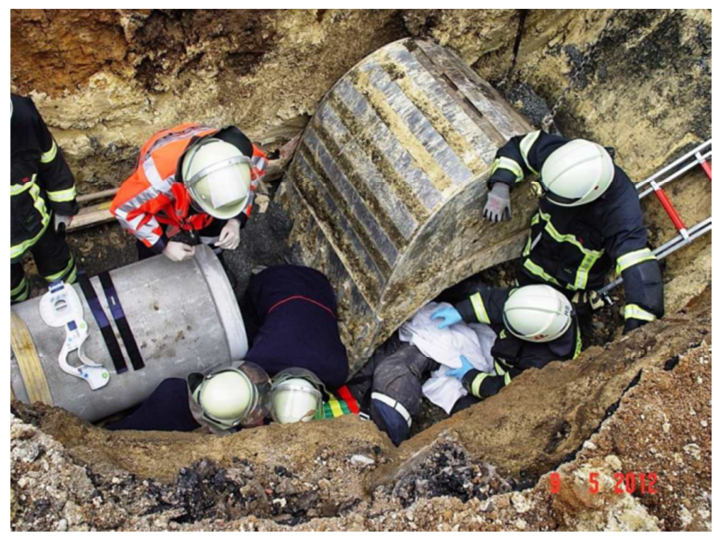

Figure 3. Worker pinned by detached bucket [8] 


\subsection{Safety Statistics}

Over time the number of different quick couplers has multiplied and so have accidents. Fatalities have occurred due to attachments being accidentally (or partially) released from work equipment during operation. Safety statistics from Germany report that 18 out of 287 reported accidents with earthmoving equipment between 2009 and 2012 were caused by quick coupling systems. $17 \%$ of these resulted in fatalities [9]. Reports from many countries state that released buckets, for example, have hit bystanders causing fatal injuries. Detailed safety statistics are missing though [1]. The causes of the fatal accidents are not always the same and the views of safety authorities in different countries differ on how to reduce and report risk. UK's Health and Safety Executive (HSE) analysed the accident data and concluded that all of the known fatalities were caused by the operator not inserting the safety pin in semi-automatic couplers. Even without the safety pin inserted the buckets would not have been released unless there had been a failure of some part of the mechanism, or some error by the operator.

\subsection{Acts, Standards, and Best Practices}

Pursuant to the US Occupational Safety and Health Act employers "must comply with hazard-specific safety and health standards publicized by OSHA or by a state with an OSHA-approved state plan" [4]. Employers must also provide employees with a workplace free from recognized hazards likely to cause death or serious physical harm.

Standards that exist or are in review in many countries, like the European Norm EN-474, the International Organizations for Standardization ISO 13031, Standards Australia AS 4774 - 2008, and United Kingdom's Lifting Operations and Lifting Equipment Regulations (LOLER) 1998, also place a responsibility on manufacturers to provide adequate mounting, locking, and checking procedures [10-11] Employers have a legal responsibility to ensure that their employees are using safe equipment and failure to do so can lead to criminal proceedings.

Some large contractors and even entire countries, like Switzerland and the UK, have banned the sale or use of some (semi- or) automatic quick coupler systems due to the related safety hazards [11]. Certain quick coupling devices appeared to endanger the loss of the attachment device. Therefore the Swiss Federal Accident Insurance (SUVA) enacted a sales prohibition for these devices starting from 1st of January 2016 [12]. The enactment has since been contested in federal court by the Association of Swiss Construction Equipment [13].

While other countries ask for safer design, companies have written their own specifications to pursue safety via a procurement policy. Best practices issued within many construction companies are one way in the safe use of quick couplers. They also, if followed carefully through, provide equipment operators and workers-on-foot with adequate education and training on safety-related hazards, in particular in earthmoving or lifting operations. A few best practices to prevent unintended bucket releases, which can result in death or injury:

1. Only use existing couplers providing a secondary system to retain the attachment and ensure the safety pins are correctly installed.

2. Always consider the existing standards, e.g. EN-474 on the installation, use, testing, inspection and maintenance of quick couplers. They "shall not release the attachment by malfunction or loss of engagement force" [10].

3. Inspect the quick couplers frequently, like it is done regularly for any other lifting equipment.

4. Minimize opportunities for operator error as much as possible, e.g. provide frequent training.

5. Keep workers-on-foot away from equipment.

6. (Some equipment manufacturers voluntarily) Ban the sale of semi-automated couplers.

\section{State-of-the-Art of RFID in Safety and Quick Coupling Systems}

The authors introduce a prototype implementation of a radio frequency identification (RFID)-based attachment identification system with focus on a comprehensive evaluation of the system [14-16], especially considering the harsh environment a high-end technology is typically exposed to on construction sites.

The particular application of passive RFID systems in construction safety has been widely explained by various research groups [17-25]. These articles contain technical explanations and current limitations of the technology vs. competing approaches.

Regarding specifically the identification and management of excavator attachments there are two patented solutions available [26-27]. Both solutions use low radio frequency identification (LF-RFID), where tag and reader are integrated in the quick coupler. However, the LF-RFID technology-based solution is associated with a number of disadvantages:

a. For use in combination with a tilt rotator, the cables of the reader need to run through the tilt rotator to reach the installation position in the quick coupler. There it is exposed to enormous forces and the harsh environment.

b. Since the system is integrated in the quick 
coupler, it is sold by the manufacturer of the quick coupler. A vendor-neutral retrofitting option is not available.

\section{Design of RFID System and Experiments to Identify Attachments}

To mitigate the above-mentioned disadvantages, a concept is proposed of an attachment identification system using passive UHF-RFID technology, which identifies the attachment while the coupling process takes place. Due to an increased reading range of commercially-available RFID antennas, it is not necessary to integrate the reader in the quick coupler. Instead, the antenna can be mounted on the excavator itself. Consequently, the proposed system is easy to install. Retrofitting existing equipment is easily possible.

The challenges which arise by using the UHF passive RFID technology for an attachment identification system in metal environments are signal multipath and read range. The proposed design therefore requires design implementation and experimental verification.

To verify the technical feasibility, a systematic testing procedure was applied. A hierarchical, structured approach was designed by the Center of RFID Applications Munich [28] on the basis of the established standards for testing RFID systems [29-30]. The specific characteristics of this approach lie in a threestage procedure to verify particular application scenarios. The test approach is divided into the following three steps: (a) laboratory tests (synthetic tests), (b) practically-oriented tests (semi-synthetic tests) and (c) realistic field tests.

The laboratory tests consist of basic measurements with commercially-available RFID hardware, tags, and surface materials. They are carried out in a radiofrequency anechoic chamber without any external wireless interference. It provides the space for evaluating if RFID equipment offers an appropriate solution to identifying tags located on the attachment.

The core activity of the practically-oriented tests is the systematic variation of the system parameters to evaluate the general feasibility of the application. These tests take place in a simulated experimental environment. At this stage of testing, the application of relevant environmental influence factors, like reflections or interferences, have already been considered.

The last step of the designed testing procedure comprises of the verification of the previous generated testing results in the field under real application conditions.

The RFID reader was installed on the machine in the equipment cabin in order to allow an easy integration into mobile computing, power supply and to ensure a safe location to protect it from the harsh environmental constraints. The reader-antenna and tag on the attachment are variable in mounting position. Several commercially-available tag types that work well on metallic surfaces were tested.

Practically-oriented tests then dealt with evaluating the different mounting positions and their performance. An abstract test environment containing only RFID antenna, excavator bucket incl. tilt-rotator, and passive RFID tag was selected (see Figure 4). Three significantly different mounting positions of the tag were evaluated (see Figure 5).

The first tag-position, denoted by TP1, mounts the tag on the side of the attachment's quick coupling adapter plate. The advantage of this position is that it applies to a large variety of attachments and promises a uniform mounting. Furthermore, the location protects the tag from the worst external forces (i.e., dirt, dust, water, ultraviolet light exposure). A variation of this mounting position is TP $1-30^{\circ}$ angle. The tag's position is analog to TP1-no angle except that it is being mounted at an angle of $30^{\circ}$ against the adapter plate.

TP2 mounts the tag on the front side of the adapter plate. The front side has the advantage that it is exposed more directly to the antenna's reading field. On the other hand, the installation is more troublesome as there is very little space available.

Location TP3 places the tag on the front face of the bucket's connecting bolt. This again, allows for good exposure to the reading field, but has the disadvantage of risking physical damage to the RFID tag as operators use this location to slightly move or push the attachment with the excavator stick.

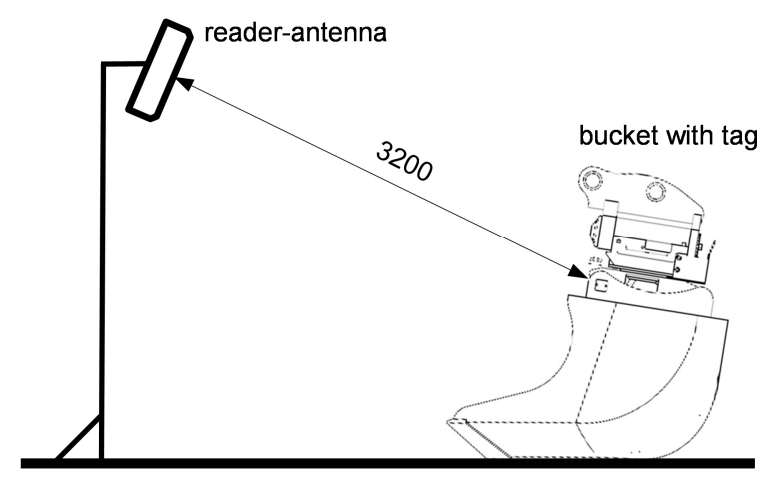

Figure 4. Schematic test set-up for semisynthetic tests including RFID antenna and tag 


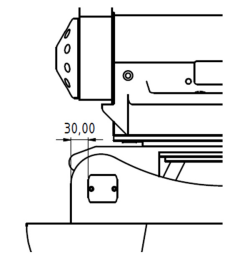

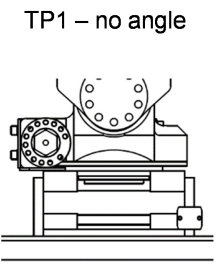

TP2

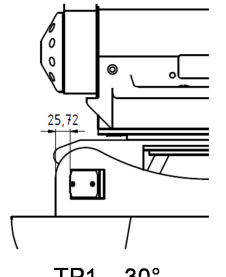

TP1 $-30^{\circ}$

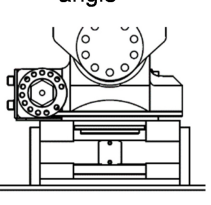

TP3
Figure 5. Passive RFID tag mounting positions

Additional consideration was given to the boom of the excavator. An equivalent metallic object inserted in the measurement space interfered the line-of-sight (LOS) between reader and tag (see Figure 6).

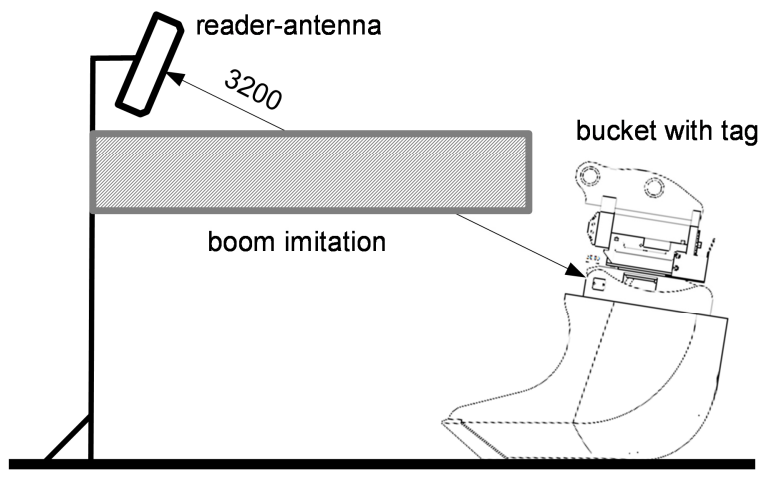

Figure 6. Schematic test setup for semi-synthetic test featuring an interference through a boom

In addition, field-realistic tests on a real excavator needed to be performed. Three significantly different mounting positions for the reader-antenna devices were analyzed (see Figures 7-9).

The first position, denoted by RP1, is located inside the operator's cab. Thereby reader and antenna are protected from the harsh environmental constraints. RP2 placed the antenna on the outside of the operator's cab. The advantage of this placement is an obstruction-free LOS. On the other hand, the hardware is no longer protected from the natural environment and theft. RP3 placed an integrated mobile reader/antenna system on the boom, offering more direct LOS on the attachment. A trade-off between LOS and protection of the hardware influences final decision making, especially when retrofitting existing machines.

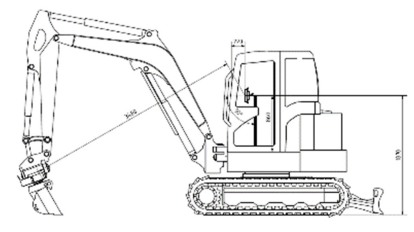

RP1

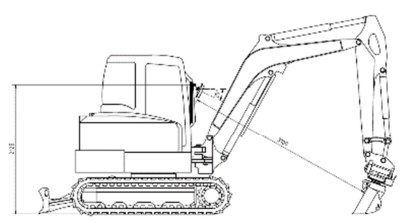

RP2

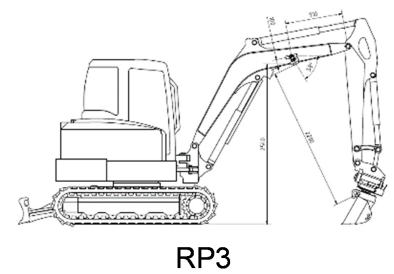

Figure 7. Mounting positions of reader-antenna

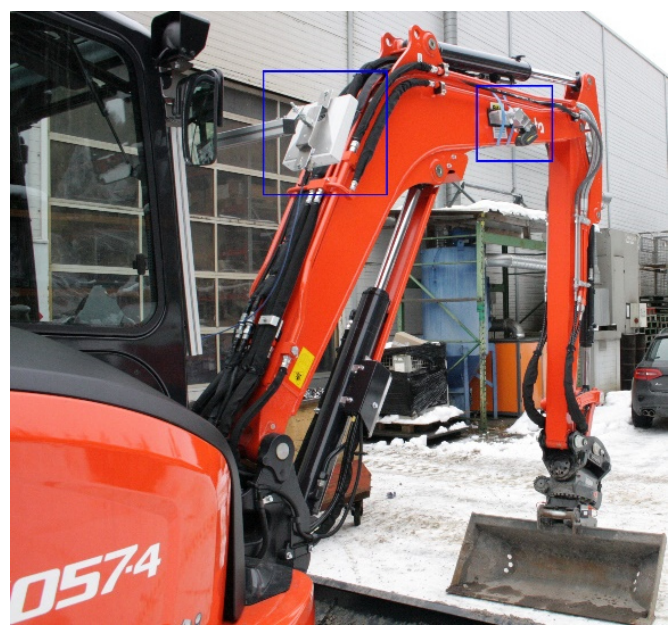

Figure 8. Mounting positions of antennas at the excavator's cabin and on the boom

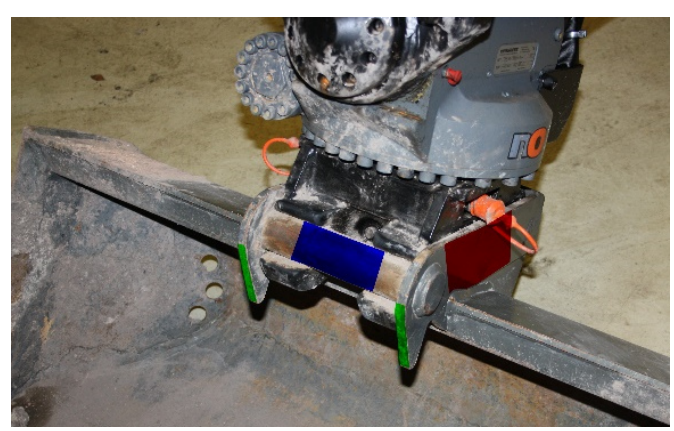

Figure 9. Mounting positions of the UHF-RFID tags on bucket (illustrated in green, blue, red) 
A selection based on pre-testing on metallic surfaces and rugged housing of three passive RFID tags was done:

- RFcamp, Titan Fastener, Alien Higgs 3, 148 x $18 \times 3.1 \mathrm{~mm}$

- Confidex Ironside, NXP UCODE G2XM, 51.5 x 47.5 x $10.0 \mathrm{~mm}$

- $\quad$ SkyRFID, FR4 Harsh Environment Tag, 97 x $17 \times 3.2 \mathrm{~mm}$

The proposed three step systematic testing procedure was carried out for all of the three tags, however, the results presented in this article are based only on the best performer: Confidex Ironside.

The semi-synthetic as well as the practical field tests were carried out with three reader/antenna systems:

- a laboratory-like RFID measurement solution (type: Voyantic, Tagformance Lite) for the evaluation of the functionality and performance (read range and success rate) of UHF-RFID systems,

- a stationary, industrial-quality reader (type: CAENRFID, R4300P) for verifying the feasibility of deployment in an industrial context for semi-synthetic tests and practical tests RP1 and RP2, and

- a mobile reader with integrated antenna (type: Technology Solutions, TSL 1097) which verified the feasibility of deployment in an industrial context regarding RP3

The test results to both reader/antenna systems (lab and industrial) are shown in Tables 1 and 2. Comparing the four different tag mounting positions, the results of the lab system correlate well to the results of the industrial system. Furthermore, the results of TP1 and TP3 are quite promising whereas TP2 fails to provide reading events. In accordance with the expectations from theory, adding the boom imitation to the test set-up deteriorates the results of the lab system. In contrast to that and against the expectations, the influence of the boom does not show notable impact on the results of the industrial system.

The practical field test results were conducted in a typical application scenario using a 5.5 ton excavator (type: Kubota KX057-4). Table 3 shows the aggregated experimental test result matrix. The test results of the field trial show that the mounting position TP1 with the tag at a $30^{\circ}$-angle achieves good reading results using the industrial system. . Regarding the results of the industrial system of TP2 and TP3 the results are inferior to TP1, whereat TP2 presents the worst results. In addition, the practical relevance of these two positions is comparatively low.

Table 1: Results of semi-synthetic tests

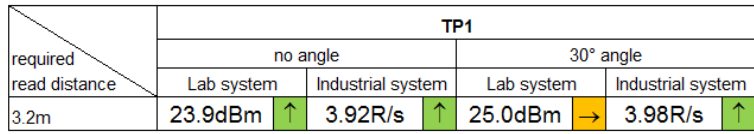

\begin{tabular}{|c|c|c|c|c|}
\hline \multirow{2}{*}{$\begin{array}{l}\text { required } \\
\text { read distance }\end{array}$} & \multicolumn{2}{|c|}{ TP2 } & \multicolumn{2}{|c|}{ TP3 } \\
\hline & Lab system & Industrial system & Lab system & Industrial system \\
\hline $3.2 \mathrm{~m}$ & - & - & $15.9 \mathrm{dBm}$ & $3.94 \mathrm{R} / \mathrm{s}$ \\
\hline
\end{tabular}

Legend: Lab system: Required power for reading event, max. system power: $30 \mathrm{dBm}$ Industrial system: for stabil system reading ratio $>=1.5$ Reads $/ \mathrm{s}$

Table 2: Results of semi-synthetic tests featuring interference through a metallic boom

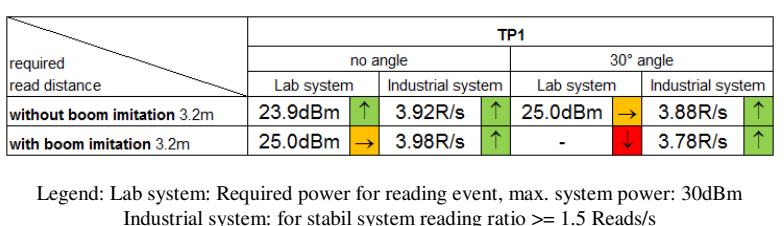
ndustrial system: for stabil system reading ratio $>=1.5$ Reads $/ \mathrm{s}$

Table 3: Results of practical field tests

\begin{tabular}{|c|c|c|c|c|c|c|c|}
\hline \multirow{3}{*}{$\begin{array}{l}\mathrm{RP+} \\
\text { required } \\
\text { read distance }\end{array}$} & \multicolumn{7}{|c|}{ TP1 } \\
\hline & \multicolumn{3}{|c|}{ no angle } & \multicolumn{4}{|c|}{$30^{\circ}$ angle } \\
\hline & \multirow{2}{*}{ Lab system } & \multicolumn{2}{|r|}{ Industrial system } & \multicolumn{2}{|l|}{ Lab system } & \multicolumn{2}{|c|}{ Industrial system } \\
\hline RP1 $3.5 \mathrm{~m}$ & & & - & - & $\downarrow$ & $1.38 \mathrm{R} / \mathrm{s}$ & $\rightarrow$ \\
\hline RP2 $3.0 \mathrm{~m}$ & - & $\downarrow$ & - & $24.0 \mathrm{dBm}$ & $\uparrow$ & $3.63 \mathrm{R} / \mathrm{s}$ & $\uparrow$ \\
\hline RP3 $2.2 \mathrm{~m}$ & $23.1 \mathrm{dBm}$ & \multicolumn{2}{|c|}{\begin{tabular}{c|c}
$\uparrow$ & reading event $\uparrow$
\end{tabular}} & $25.5 \mathrm{dBm}$ & \multicolumn{3}{|c|}{$\rightarrow$ reading event 1} \\
\hline & \multicolumn{3}{|c|}{ TP2 } & \multicolumn{4}{|c|}{ TP3 } \\
\hline read distance & \multicolumn{2}{|l|}{ Lab system } & Industrial system & \multicolumn{2}{|l|}{ Lab system } & \multicolumn{2}{|c|}{ Industrial system } \\
\hline RP1 $3.5 \mathrm{~m}$ & - & & - & $23.2 \mathrm{dBm}$ & $\uparrow$ & $1.54 \mathrm{R} / \mathrm{s}$ & $\uparrow$ \\
\hline RP2 $3.0 \mathrm{~m}$ & $27.1 \mathrm{dBm}$ & $\rightarrow$ & - & $25.6 \mathrm{dBm}$ & $\rightarrow$ & $1.32 \mathrm{R} / \mathrm{s}$ & $\rightarrow$ \\
\hline RP3 $2.2 \mathrm{~m}$ & $28.2 \mathrm{dBm}$ & $\rightarrow \mathrm{re}$ & eading event $\uparrow$ & $20.7 \mathrm{dBm}$ & $\mid \uparrow$ & - & \\
\hline
\end{tabular}

Legend: Lab system: Required power for reading event, max. system power: $30 \mathrm{dBm}$ Industrial system: for stabil system reading ratio $>=1.5$ Reads/s (RP1, RP2); sucess of reading event (RP3)

Comparing the results of the lab and industrial system, no absolute consistency in readings can be concluded when using UHF-RFID tags. Similar to the test set-up with the boom imitation, the test result does not match the expected results following the theory. In only $58 \%$ of the tests, both systems achieved the same evaluation index. In about $38 \%$ of all required readings, the systems had no readings. This can be interpreted that the system requires further modification to achieve an acceptable read rate. The metallic interferences, among others are a likely reason for the poor tag read performance. Alternative technologies that yet have to be tested might improve the read rate of reader/antenna and tag-based attachments systems. 


\section{Conclusions and Future Work}

The goal of this research work was to design an experimental test methodology that fits to the evaluation of tag-based equipment attachment identification. The developed approach was verified using passive UHFRFID technology in excavator attachment identification. As such, the contribution of this research is that the methodology can be tested on other technologies, including the few, existing proprietary and original equipment manufacturer (OEM) LF-RFID solutions.

After preliminary tests identified potential mounting positions for the RF antenna and tags, their applications have been thoroughly evaluated. Considering the practical feasibility of TP2 and TP3, none of the tested scenarios proved to be a suitable to find a reliable answer to the challenge $-100 \%$ identification of attachment from a commercially-available UHF RFID reader/antenna/tag-based identification system.

Although several tests prove the general feasibility of the tag-based attachment identification approach, an industrial-type solution would also have to cater for non-readings, e.g. by providing a rugged humanmachine interface (HMI) that allows an operator to manually select the attachment from a pre-defined list when the deployed system fails (i.e., when it cannot identify the attachment automatically).

In order to resolve this matter, further research is needed. As the recent literature has stated, redesigning the construction process including novel equipment design may solve the issue [31]. An additional approach could be the use of other, emerging technologies, for example active or semi-active RFID or GPS technology. Disadvantages of such technology, for example, imprecise read ranges and simultaneous identification of other or nearby attachments should be strictly avoided. In addition, battery-powered tags may fail in longer operation lifecycles, especially in the harsh construction environment where battery power drains quickly, e.g., due to changes in the temperatures. Approaches like they have been introduced by Thomas et al. [32] and Teizer [33] are to be preferred since they come batteryfree over extended periods of time, but also with an acceptable read range. Location tracking [34], line-ofsight [35], and multipath issues [36] might be solved by approaching the lower frequency spectrum.

\section{References}

[1] Hinze, J.W., and Teizer, J., Visibility-Related Fatalities Related to Construction Equipment, Safety Science, Elsevier, 49(5):709-718, 2011.

[2] Nilssoin, N. and Stockhaus, S., Benefits of Quick Couplers for Excavators with Front Pin Lock
Technology, White paper, http://steelwrist.com, Accessed: 01/11/2014.

[3] Construction Plant-Hire Association, Safe Use of Quick Hitches on Excavators, http://www.cmeig.com.au/documents/safeuseofqui ckhitchesonexcavators.pdf, Accessed 16/01/2015.

[4] Occupational Safety and Health Administration, Hazards of Inadequately Securing Hydraulic Excavator Buckets When Using Quick Coupling Devices, SHIB 07-22-2005, 2005.

[5] Marks, E., Teizer, J., and Hinze, J., Near Miss Reporting Program to Enhance Construction Worker Safety Performance", Construction Research Congress, May 19-21, 2014.

[6] Center for Disease Control and Prevention, Preventing injuries when working with hydraulic excavators and backhoe loaders. http://www.cdc.gov/niosh/docs/wpsolutions/2004-107, Accessed: 01/11/2014.

[7] Miller UK Ltd., Confused about quick couplers? http://www.millergroundbreaking.com, Accessed: 20/10/2014.

[8] Clemens, R., Baggerschaufeln: Die tödliche Gefahr On-line: http://www.gesunde-bauarbeit.de, Accessed: 31/05/2014.

[9] Leisering, H., Untersuchte Unfälle Erdbau, 01.01.2009 bis 31.12.2012, BG Bau, Präsentationsfolien, 2012.

[10] Speck J., Europäische Sicherheitsnormen für Planiergeräte, Lader, Baggerlader, Hydraulikbagger und Muldenfahrzeuge http://www.baumaschine.de/fachzeitschriften/bau maschinen/bauportal_dateien/1996/heft1/a024_061 .pdf, Accessed: 15/01/2015.

[11] Health and Safety Executive, LOLER 2998, http://www.hse.gov.uk/work-equipmentmachinery/loler.htm, Accessed: 16/01/2015.

[12] Isik, S., Schnellwechseleinrichtungen können tückisch sein, Die Baustellen, Fachzeitschrift für Hoch-/Tief- und Spezialbau, Nr. 06, 2014.

[13] VSBM - Verband der Schweizerischen Baumaschinenwirtschaft, Zulässiger Vertrieb von Schnellwechseleinrichtungen, Replik des VSBM zum Artikel "Schnellwechseleinrichtungen können tückisch sein", 2014.

[14] Günthner, W.A. and Schneider, O., RFID-Einsatz in der Baubranche, Institute of Material Handling, Material Flow and Logistics, Garching, 2011.

[15] Rinneberg, S., Kessler, S, Günthner, W.A., 
Conceptual Approach and Evaluation of an Attachment Identification System for Excavators based on Passive Radio Frequency Identification Technology, in IEEE RFID, 2015.

[16] Rinneberg, S., Kessler, S., Günthner, W.A., Potenziale der RFID-Technologie in der Bau Branche: Identifikation von Anbauwerkzeugen, in VDBUM Großseminar, 2015.

[17] Teizer, J. Allread, B.S., Fullerton, C.E. and Hinze, J., Autonomous pro-active real-time construction worker and equipment operator proximity safety alert system, Automation in Construction, Elsevier, 19(5): 630-640, 2010.

[18] Marks, E. and Teizer, J., Real-Time Proactive Equipment Operator and Ground Worker Warning and Alert System in Steel Manufacturing, Iron \& Steel Technology, 9(10):56-69, 2012.

[19] Marks, E. and Teizer, J.. Method for Testing Proximity Detection and Alert Technology for Safe Construction Equipment Operation, Construction Management and Economics, Taylor $\&$ Francis, Special Issue on Occupational Health and Safety in the Construction Industry, 31(6): 636-646, 2013.

[20] Kelm, A., Laußat, L. Meins-Becker, A., Platz, D., Khazaee, M.J., Costin, A.M., Helmus, M. and Teizer, J., Mobile passive Radio Frequency Identification (RFID) portal for automated and rapid control of Personal Protective Equipment (PPE) on construction sites, Automation in Construction, Elsevier, 36:38-52, 2013.

[21] Costin, A., Pradhananga, N., and Teizer, J., Leveraging Passive RFID Technology for Construction Resource Field Mobility and Status Monitoring in a High-Rise Renovation Project", Automation in Construction, Elsevier, 24:1-15, 2012.

[22] Song, J., Haas, C.T., Caldas, C.T., A proximitybased method for locating RFID tagged objects, Advanced Engineering Informatics, Elsevier, 21(4):367-376, 2007.

[23] Carbonari, A., Naticchia, B., Giretti, A. and De Grassi, M. A Proactive System for Real-time Safety Management in Construction Sites, Proceedings of the 26th ISARC, pages 47-54, 2009.

[24] Chae, S., Development of Warning System for Preventing Collision Accident on Construction Site, Proceedings of the 26th ISARC, pages 55-60, 2009.

[25] Chae, S. and Yoshida, T., Application of RFID technology to prevention of collision accident with heavy equipment, Automation in Construction, Elsevier, 19(3):368-374, 2010.

[26] Liebherr-Hydraulikbagger $\mathrm{GmbH}$, Baumaschine mit Schnellwechsler, Germany. Petty Patent DE 20 2004002541 U1, August 11, 2005

[27] OilQuick AB, A system comprising an implement attachment means and an implement, Patent PCT/SE2004/000199, August 26, 2004.

[28] Fischer, R., Salfer, M. and Wölfle, M., Structured testing of RFID-systems / Strukturiertes Testen von RFID-Systemen, Einblick in AutoID/RFID, pages. 32-33, 2010.

[29] ISO 18047-6, Information technology - Radio frequency identification device conformance test methods, Part 6: Test methods for air interface communications at $860 \mathrm{MHz}$ to $960 \mathrm{MHz}, 2006$.

[30] VDI 4472-10, Requirements to be met by transponder systems for use in supply chain - Test methods to check the performance of transponder systems (RFID), 2007.

[31] Bock, T., and Linner, T., Robot Oriented Design, Design and Management Tools for the Deployment of Automation and Robotics in Construction, Cambridge University Press, 2015.

[32] Thomas, S.J., Wheeler, E., Teizer, J., and Reynolds, M.S. Quadrature Amplitude Modulated Backscatter in Passive and Semipassive UHF RFID Systems, IEEE Transactions on Microwave Theory and Techniques, 60(4):1175-1183, 2012.

[33] Teizer, J., Wearable, Wireless Identification Sensing Platform: Self-Monitoring Alert and Reporting Technology for Hazard Avoidance and Training (SmartHat), ITcon, 2015.

[34] Pradhananga, N. and Teizer, J., Cell-based Construction Site Simulation Model for Earthmoving Operations using Real-time Equipment Location Data, Visualization in Engineering, Springer, 2015.

[35] Teizer., J., Safety 360: Surround View and Alerts to Protect Workers from Hazardous Equipment, Proceedings of the 32nd International Symposium on Automation and Robotics in Construction, Oulu, Finland, 2015.

[36] Teizer, J., Magnetic Field Proximity Detection and Alert Technology for Safe Heavy Construction Equipment Operation, Proceedings of the 32nd International Symposium on Automation and Robotics in Construction, Oulu, Finland, 2015. 